\title{
Role of B-Scan Ultrasonography in Evaluating Posterior Segment of the Eye in the Event of Non Visualization of Fundus
}

\author{
Authors \\ Dr Ridham Nanda, Dr Dinesh Gupta, Dr Priyanka Sodani \\ Postgraduate Department of Ophthalmology, Government Medical College, Jammu \\ Corresponding Author \\ Dr Ridham Nanda \\ House No. 49, Denis Gate, Near Mansar Hotel, Jammu - 180001, J\&K, India \\ Mob: 9419617971, Email: ridznanda@gmail.com
}

\begin{abstract}
Background: Evaluation of posterior segment of eye in hazy ocular media is difficult ophthalmoscopically. $B$-scan ultrasonography is an important tool in such cases.

Purpose: To evaluate the status of the posterior segment of eyes in patients with opaque ocular media due to any reason.

Materials and Methods: This prospective study was conducted in the Ophthalmology department of a tertiary care hospital over a period of one year from November 2015 to October 2016, on two hundred patients presenting with opaque ocular media. After detailed history and clinical examination, B-scan ocular examination was done using ultrasound machine - Nidek US-4000 (Echoscan) with the contact method. Data was entered in Microsoft excel and Chi Square test was used for statistical analysis.

Results: Out of 200 patients, 141 (70.5\%) were males and 59 (29.5\%) -females. The patients had an age range between 6 months to 90 years. The mean age was $47.845 \pm 22.95$ years. Majority of patients (34\%) were in the age group $\geq 61$ years. The most common indication of ocular sonography in our study was opaque media due to lenticular opacity (48.5\%). One hundred eight patients (54\%) did not demonstrate any posterior segment pathology on B-scan echography. Two most common posterior segment lesions found in our study were vitreous haemorrhage (VH) - 18.50\% and retinal detachment $(R D)$ combined with vitreous disorders- $8 \%$, respectively. Other B-scan findings were isolated retinal detachment group which comprised $7 \%$, retinoblastoma $-1.5 \%$ patients, total choroidal detachment $(1.5 \%)$, endophthalmitis $(1 \%)$, dislocated PCIOL in vitreous (1\%) and phthisis bulbi $-0.5 \%$.

Conclusion: B scan ultrasonography is an indispensible tool in examination of posterior segment in patients with opaque ocular media, where a preoperative fundoscopic evaluation is virtually impossible.

Keywords: B scan, posterior segment, opaque ocular media
\end{abstract}

\section{INTRODUCTION}

Ultrasound is an acoustic wave that consists of oscillation of particles. By definition ultrasound waves have frequency greater than $20 \mathrm{kHz}$. For diagnostic ophthalmic ultrasound, frequencies used are generally in the range of 8 to $10 \mathrm{MHz}$. These very high frequencies used in ophthalmology produce short wavelengths. These very short wavelengths allow resolution of minute structures in the eye and orbit. 
The superficial location of eye, its cystic composition, and the advent of high frequency ultrasound make B scan ultrasonography ideal for imaging the eye.

Examination of the intraocular contents by ophthalmoscopy is dependent upon transparent light conducting media: the cornea, the aqueous humour, the lens and vitreous gel.

Situations that prevent normal examination of fundus include:

$>$ Lid problems (e.g. Severe edema, partial or total tarsorrhaphy)

$>$ Corneal opacities (e.g., scars, severe edema)

$>$ Abnormal contents of anterior chamber (hyphema, hypopyon)

$>$ Abnormalities of pupil- miosis, papillary membrane

$>$ Dense cataracts, mature cataract

$>$ Vitreous opacities including vitreous hemorrhage, asteroid hyalosis, synchysis scintillans, inflammatory debris, membranes such as seen in retinitis proliferanes and viteroretinal traction, foreign bodies and organized blood.

$>$ Posterior vitreous detachment

$>$ Retinal detachment

$>$ Choroidal effusion, choroidal detachment

$>$ Intraocular tumors especially retinoblastoma

$>$ Intraocular foreign bodies

In such cases, diagnostic B-scan ultrasound can accurately image intraocular structures and give valuable information on the status of the lens, vitreous, retina, choroid, and sclera.

Typically, ultrasonography is more accurate than any radiographic technique in the assessment of choroidal lesions, intravitreal differential diagnosis, retinal detachment, proliferative membranes, and intraocular tumor heights ${ }^{[1]}$.

Timely detection of significant posterior segment abnormalities using ultrasound prior to cataract surgery helps to detect pathologies that may influence the surgical strategy and the postoperative visual prognosis. Studies of ultrasonographic evaluation in eyes with opaque media have shown incidence rates of posterior segment pathology to vary from $19.6 \%$ to $66 \%{ }^{[2]}$.

Ultrasonography also has the added advantage over fundoscopy in depicting the internal characteristics of a suspected tumor such as calcific foci in retinoblastoma ${ }^{[3]}$.

High frequency ocular ultrasonography is the ideal method for imaging the eye and intraocular structures. In the presence of opaque ocular media, a complete view of the fundus may be impossible ophthalmoscopically, and in these cases sonograpghy is invaluable ${ }^{[4]}$. The eye can be examined dynamically during eye movements, which is of value in localizing abnormalities ${ }^{[5]}$.

B scan USG is cost effective, which is important consideration in rural setting. In addition, it is noninvasive and easily available and the results are reproducible ${ }^{[6]}$.

\section{MATERIALS AND METHODS}

This prospective study was conducted in the ophthalmology department of a tertiary care hospital over a period of one year from November 2015 to October 2016, on two hundred patients presenting with opaque ocular media whose fundus could not be visualised.

- Before performing ultrasonographic examination, informed consent was obtained from the patients. History of trauma, working environment/tools, bleeding disorders, past medical or surgical history, decreased vision, diabetes, hypertension, vitrectomy or any other surgical procedures was noted in the proforma attached. Detailed clinical and laboratory investigations were done. Patients with high risk of or with extrusion of intraocular contents were excluded from the study.

- B-scan ocular examination was done using ultrasound machine - Nidek US-4000 (Echoscan) with the contact method. Gray scale examination was performed with appropriate control settings. Patients were examined in supine position and both eyes were scanned serially in axial, transverse as 


\section{JMSCR Vol||05||Issue||07||Page 25049-25055||July}

well as longitudinal sections. The probe was placed over closed eyelid after application of coupling gel. Patient was asked to look straight ahead with the eyes closed, but without clenching the eyelids. Dynamic scans (with the patient instructed to move the eyeball to the right, left, up or down) were carried out, when indicated. Basic screening was performed initially at high gain setting (i.e., $80 \mathrm{~dB}$ ) to detect weaker echoes followed by examination under lower sensitivity. Scan of other eye was always obtained for comparison.

Data was entered in Microsoft excel and Chi Square test was used for statistical analysis.

\section{RESULTS}

Figure 1. Showing sex distribution of patients

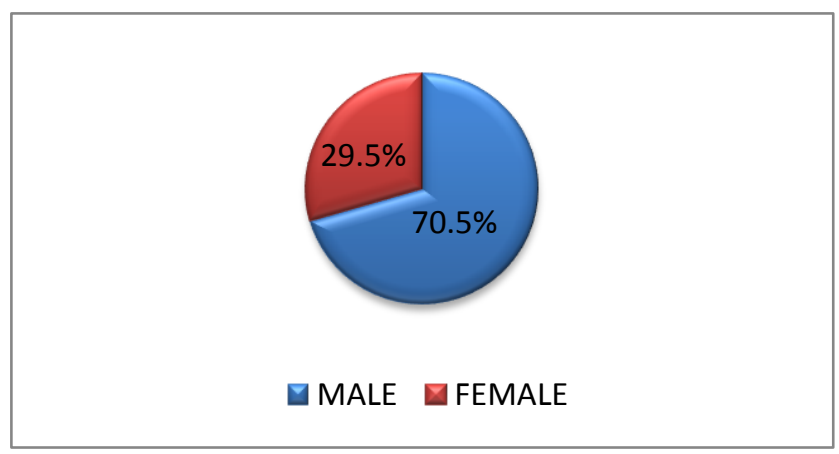

Figure 2 showing total RD: B-scan showing funnel shaped total RD with anterior attachment at ora serrata and posterior attachment at optic nerve head. Few secondary cystic changes are also seen in retinal membrane

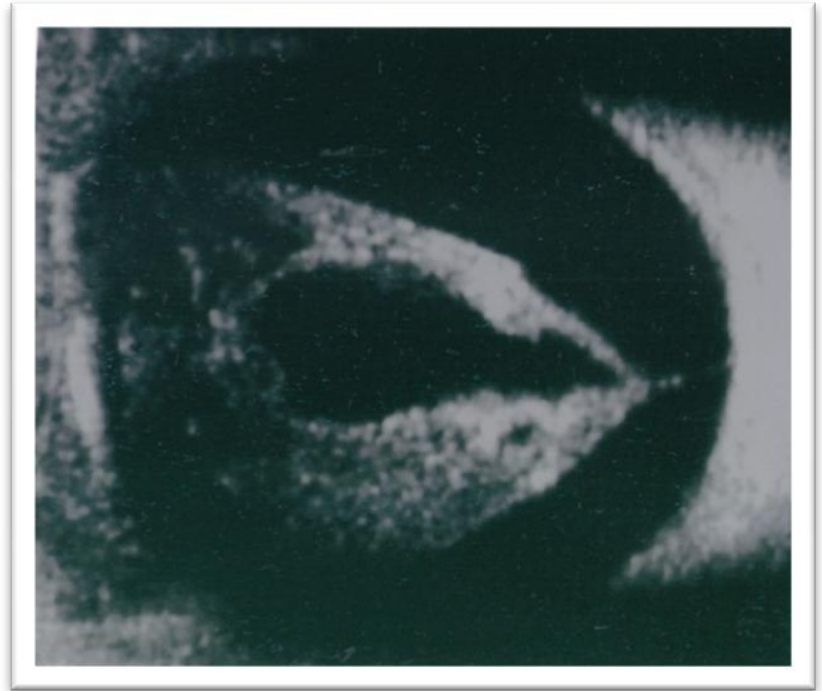

Age range of patients: 6months to 90 years

The mean age of the patients was $47.845 \pm 22.95$ years. The maximum number of patients $68(34 \%)$ was in the age group $\geq 61$ years.

Figure 3 Showing age and sex distribution of patients

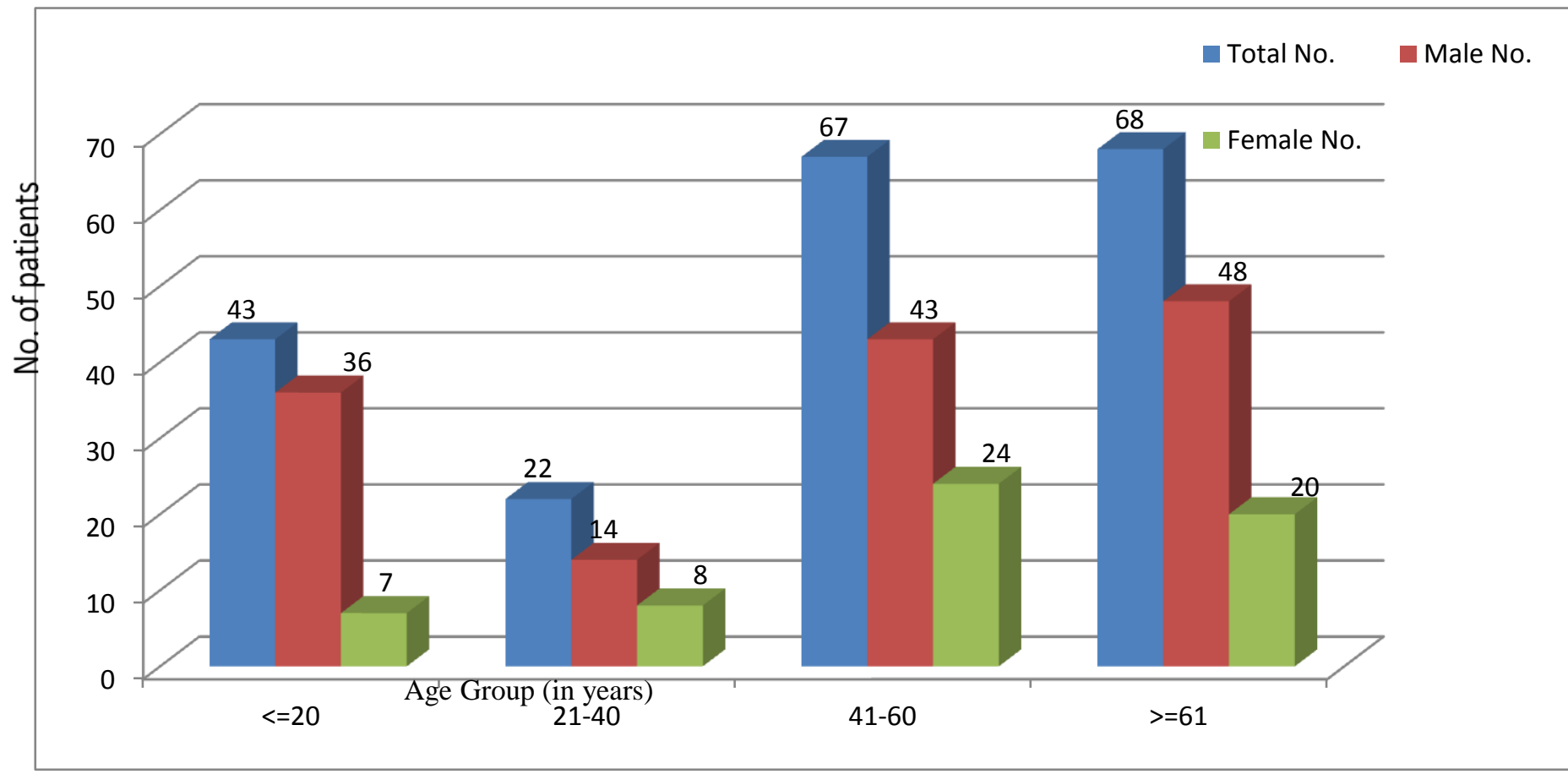


Table 1 Showing indications of ocular ultrasonography

\begin{tabular}{|l|c|c|}
\hline Indications & $\begin{array}{c}\text { No. of } \\
\text { patients }\end{array}$ & $\begin{array}{c}\text { Percentage } \\
(\mathbf{\%})\end{array}$ \\
\hline $\begin{array}{l}\text { Suspected vitreo-retinal } \\
\text { pathology (including leukocoria) } \\
\text { on clinical examination }\end{array}$ & 37 & 18.50 \\
\hline Opaque media due to trauma & 61 & 30.5 \\
\hline $\begin{array}{l}\text { Opaque media (excluding } \\
\text { trauma cases) }\end{array}$ & 102 & 51 \\
- Lens opacity (cataract) & 97 & 48.5 \\
- Corneal opacity & 5 & 2.5 \\
\hline Total & $\mathbf{2 0 0}$ & $\mathbf{1 0 0 . 0 0}$ \\
\hline
\end{tabular}

Table 2 Showing distribution of B-scan results

\begin{tabular}{|l|c|c|}
\hline Groups & $\begin{array}{c}\text { No. of } \\
\text { patients }\end{array}$ & $\begin{array}{c}\text { Percentage } \\
(\mathbf{\%})\end{array}$ \\
\hline Normal & 108 & 54 \\
\hline Vitreous disorders & 51 & 25.50 \\
\hline $\begin{array}{l}\text { Vitreous disorders } \\
\text { combined with } \\
\text { retinal detachment }\end{array}$ & 16 & 8.00 \\
\hline Retinal detachment & 14 & 7.00 \\
\hline Intraocular tumours & 3 & 1.50 \\
\hline Miscellaneous & 8 & 4.0 \\
\hline Total & $\mathbf{2 0 0}$ & $\mathbf{1 0 0 . 0 0}$ \\
\hline
\end{tabular}

Figure 4 Showing frequency of distribution of vitreous disorders

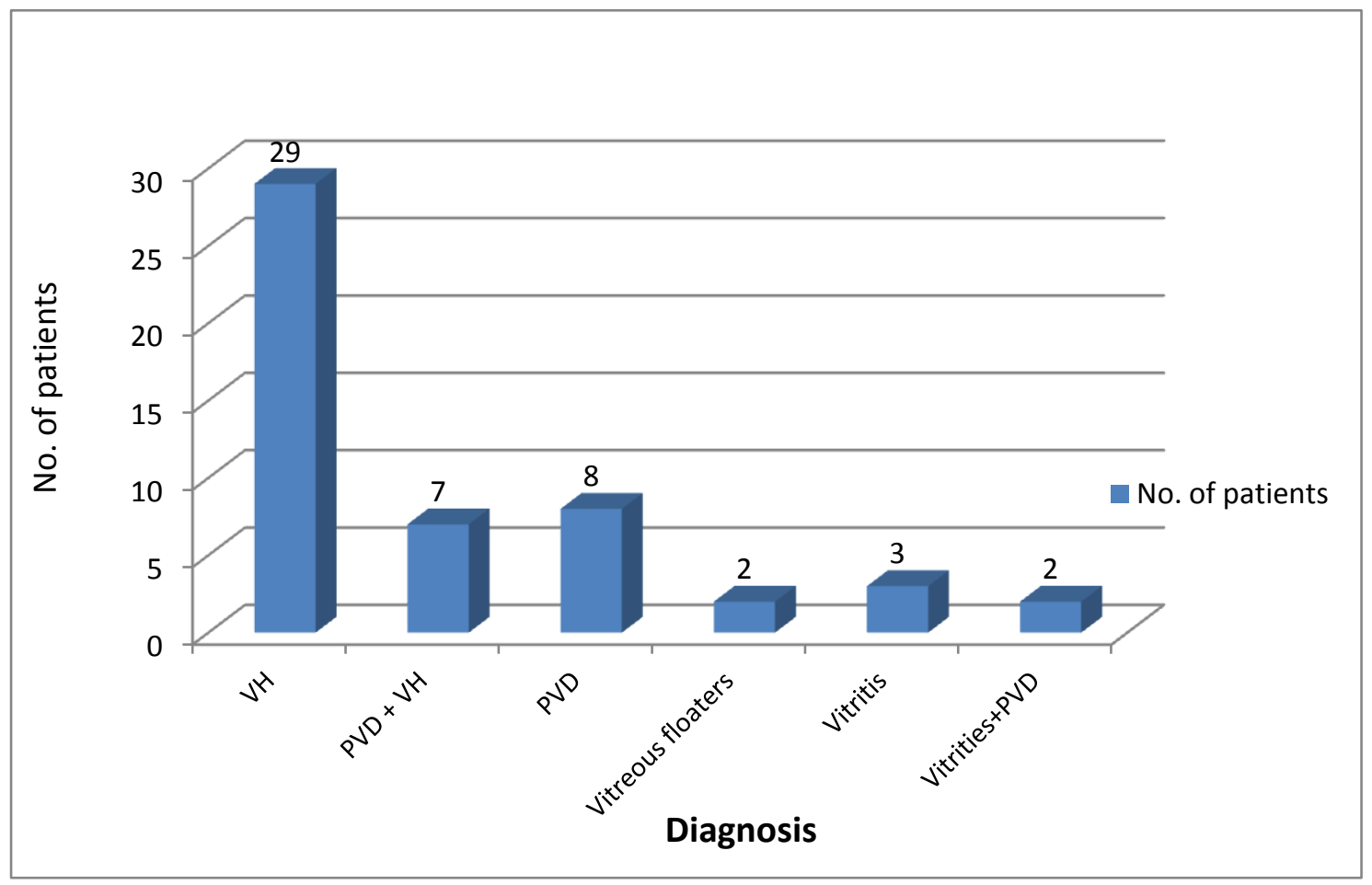

Figure 5 Showing causes of vitreous haemorrhage

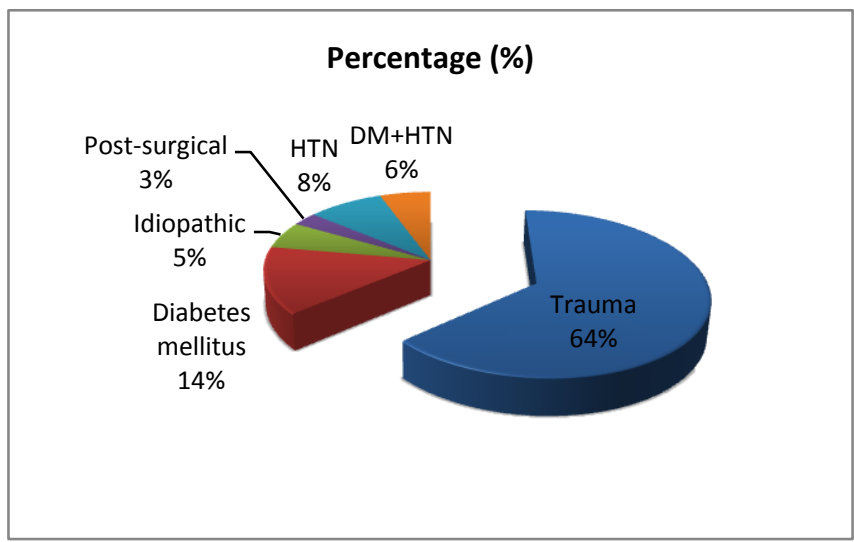

Table 3 showing frequency of various conditions placed under miscellaneous group

\begin{tabular}{|l|c|c|}
\hline Diagnosis & $\begin{array}{c}\text { No. of } \\
\text { patients }\end{array}$ & $\begin{array}{c}\text { Percentage } \\
(\%)\end{array}$ \\
\hline Choroidal detachment & 3 & 37.5 \\
\hline Endophthalmities & 2 & 25 \\
\hline $\begin{array}{l}\text { Dislocated PCIOL in } \\
\text { vitreous }\end{array}$ & 2 & 25 \\
\hline Phthisis bulbi & 1 & 12.5 \\
\hline Total & $\mathbf{8}$ & $\mathbf{1 0 0 . 0 0}$ \\
\hline
\end{tabular}


Table 4 showing association between ocular trauma and posterior segment pathology detected on B-scan

\begin{tabular}{|l|c|c|}
\hline B-Scan & $\begin{array}{c}\text { Non trauma } \\
\text { patients }\end{array}$ & $\begin{array}{c}\text { Ocular trauma } \\
\text { patients }\end{array}$ \\
\hline Normal PS & 94 & 14 \\
\hline $\begin{array}{l}\text { Posterior segment } \\
\text { pathology }\end{array}$ & 45 & 47 \\
\hline Total & 139 & 61 \\
\hline
\end{tabular}

Odds ratio $=7.013$

On applying chi square test $\left(\chi^{2}=34.06\right)$, significant association $(\mathrm{p}<0.001)$ is found between trauma and posterior segment pathology.

Figure 6 showing distribution of B-scan results among patients of ocular trauma

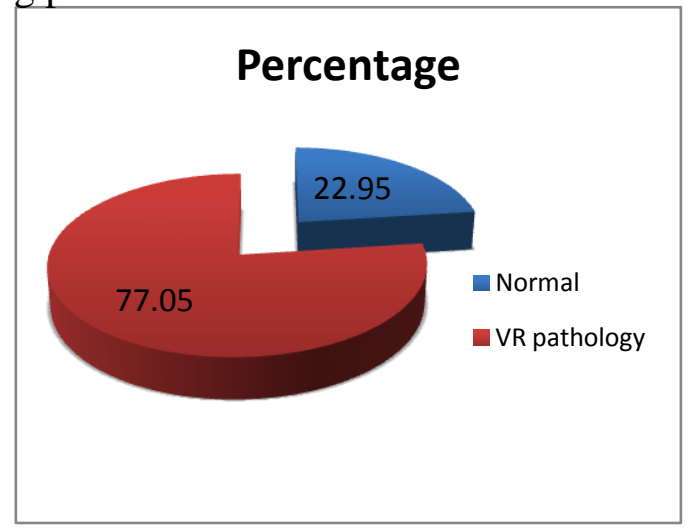

Figure 7 Dot like opacities in B-scan of vitreous haemorrhage

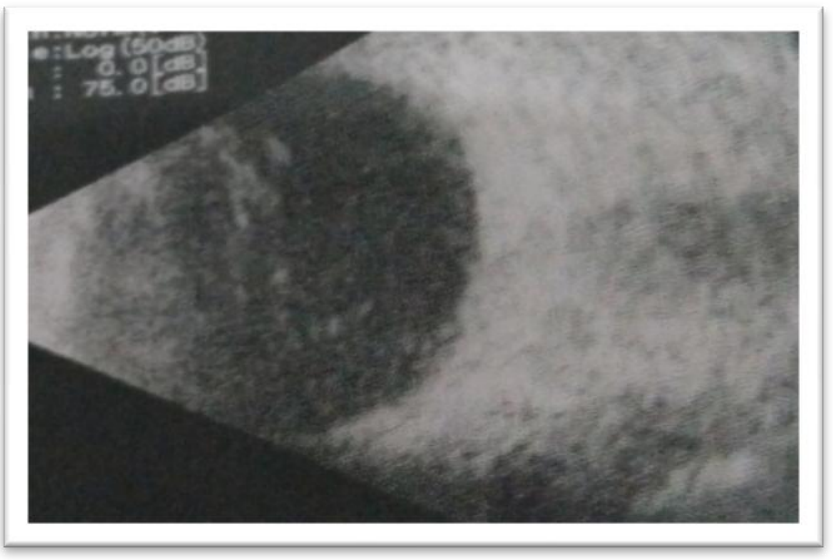

\section{DISSCUSSION}

Over the last 30 years, ultrasonography has greatly advanced and this has enabled us to study posterior segment of eye even in the presence of opaque media. Although, it can be used to detect the pathology in the anterior segment and in the orbit, but its most common use is to study the abnormalities in the posterior segment ${ }^{[7]}$.

In the present study, the maximum number of patients - $68(34 \%)$ were in the age group $\geq 61$ years. In a study by Qureshi and Laghari maximum number of patients was also present in the age group of 60-69 years ${ }^{[8]}$.

The two most common posterior segment disorders found in our study were vitreous disorders -51 patients $(25.50 \%)$ and retinal detachment in conjunction with vitreous disorders - 16 patients $(8 \%)$.

Among the vitreous disorders, vitreous haemorrhage which was seen in $29(56.9 \%)$ patients topped the list. Vitreous haemorrhage was seen as dot like echoes and membranes, predominantly in the dependant portion of vitreous cavity. Out of 29 patients of vitreous haemorrhage, 23 had history of trauma, 3 patients had diabetic eye disease, 2 were having history of cataract surgery and 1 was hypertensive. Dawood et al found 98 (44.95\%) vitreous disorders and 58 (26.60\%) retinal detachments among the total of 218 ultrasonograms performed ${ }^{[7]}$. In their series, vitreous haemorrhage (35 patients) was the commonest vitreous problem followed by posterior vitreous detachment (19 patients) and the most common cause of vitreous haemorrhage was trauma (12 out of 35 patients) followed by diabetic eye disease ( 9 out of 35 patients). Rabinowitz et al study showed that proliferative diabetic retinopathy (35\%) and ocular trauma $(33 \%)$ were the most common causes of vitreous haemorrhage ${ }^{[9]}$.

Retinal detachment (including patients of RD combined with vitreous disorders) was seen in 30 (15\%) cases. Sen et al showed an incidence of $21.34 \%$ (34 out of 164 cases examined) due to traumatic and non-traumatic causes ${ }^{[10]}$. Study by Sharma demonstrated 26 cases $(21.31 \%)$ of retinal detachment diagnosed out of 122 cases scanned ${ }^{[11]}$. Javed et al reported that out of 463 patients, the patients of retinal detachment were $68(14.70 \%)^{[12]}$. Out of 14 patients with isolated retinal detachment, $9(64.30 \%)$ had history of trauma; $2(14.28 \%)$ were myopic; 2(14.28\%) had history of cataract 
extraction and in $1(7.1 \%)$ patient the cause was not known. Of 12 patients with retinal detachment combined with vitreous haemorrhage, 6 (50\%) patients had history of trauma, $5(41.67 \%)$ had diabetes mellitus, and $1(8.33 \%)$ had history of surgery for cataract.

The third group of posterior segment disorder diagnosed in our series was intraocular tumours (1.5\%). Bilateral retinoblastoma with microphthalmos was seen in one patient. In rest two patients with unilateral retinoblastoma, echogenic mass was seen arising from retina and projecting into vitreous cavity. Highly echogenic areas of suspected calcifications were also found in the mass in both of these patients. Antero-posterior diameter of the globe was reduced $(13-14 \mathrm{~mm})$ in one patient with unilateral retinoblastoma. We could not demonstrate any retinal detachment associated with the tumor. Similar results were shown by Sen et al study where retinoblastoma formed $3 \%$ of various ocular abnormalities ${ }^{[10]}$.

The last group of posterior segment disorder diagnosed in the present study included heterogeneous conditions and all were placed under the heading of miscellaneous disorder. It included 3 cases of total choroidal detachment, 2 cases each of endophthalmities and dislocated PCIOL in vitreous; and 1 case of phthisis bulbi.

Three cases of total choroidal detachment were diagnosed in the study and two of them appeared as two echogenic convex membranes into the vitreous cavity approaching the midline but not involving the optic nerve head. One of them was haemorraghic choroidal detachment with fine echoes in the suprachoroidal space and the underlying cause identified was post operative hypotony.

Endophthalmities was diagnosed in two patients; one of these was postoperative eye and one had traumatic endophthalmitis. There was diffuse vitreous opacification with vitreous echoes and membranes and thickened and ill defined retinochoroido-scleral complex on B-scan. In endophthalmitis, opacities are similar to opacities of dispersed vitreous haemorrhage. Follow up was necessary as organization and membrane formation is faster than seen in vitreous haemorrhage. Ultrasound is useful to determine the severity and extent of inflammation in clinically suspected cases of endophthalmitis. Similar findings were reported by Maresova et al, who conducted a retrospective study in 7 eyes of 7 patients to evaluate the ultrasound findings in eyes with endophthalmitis following penetrating injury and found that membranes were present in the vitreous in 5 eyes ${ }^{[13]}$. The thickening of the choroid was present at the ultrasound examination in all seven eyes. The detachment of the choroid was not found in any eye. Maneschg et al in their study conducted a retrospective analysis of data and ultrasound findings of 81 patients with endophthalmitis following cataract surgery. Ultrasonographic findings such as membrane formation were found in 23 eyes (28\%), and dense vitreous opacities were detected in nine eyes. Posterior wall thickness was measured in 73 eyes ${ }^{[14]}$.

\section{CONCLUSION}

B scan ultrasonography can be extensively used in evaluation of vitreo-retinal disorders, in patients with opaque ocular media, where a preoperative fundoscopic evaluation is virtually impossible, for assessment of posterior segment. It is useful for preoperative planning. B-scan is reliable, safe, cheap, rapid investigation and a feasible option.

A full knowledge of ocular pathology is necessary, if B-scans are to be correctly interpreted.

In certain situations, where CT scan and MRI are more useful than B-scan ultrasonography, it is still valuable because of its economical feasibility.

\section{REFERENCES}

1. Weiss RA, Haik BG, Smith ME. Introduction to diagnostic imaging techniques in ophthalmology. Int Ophthalmol Clin 1986; 26(3):1-24

2. Anteby II, Blumenthal EZ, Zamir E, Waindim P. The role of preoperative ultrasonography for patients with dense cataract: a retrospective study of 509 cases. Ophthalmic surg lasers 1998; 29(2):114-8 
3. Verbeek AM. Differential diagnosis of intraocular neoplasms with ultrasonography. Ultrasound Med Biol 1985; 11(1):163-70

4. McNicholas MM, Brophy DP, Power WJ, Griffin JF. Ocular trauma: evaluation with US. Radiol 1995; 195(2):423-7

5. Fisher YL, Slakter JS, Friedman RA, Yannuzzi LA. Kinetic ultrasound evaluation of the posterior vitreoretinal interface. Ophthalmol 1991; 98(7):1135-8

6. Aironi VP, Gandage SG. Pictorial essay: Bscan ultrasonography in ocular abnormalities. Ind J Radiol Imaging 2009; 19 (2):109-15

7. Dawood Z, Mirza SA, Qadeer A. Role of Bscan ultrasonography for posterior segment lesions. Pak J LUMHS 2008; 07(1):7-12

8. Qureshi MA, Laghari K. Role of B-scan ultrasonography in preoperative cataract patients. Int J Health Sci 2010; 4(1):31-37

9. Rabinowitz R, Yagev R, Shoham A, Lifshitz $\mathrm{T}$. Comparison between clinical and ultrasound findings in patients with vitreous hemorrhage. Eye 2004; 18(3):253-6

10. Sen KK, Parihar JKS, Saini M Moorthy RS. Conventional B-mode ultrasonography for the evaluation of retinal disorders. MJAFI 2003; 59:310-12

11. Sharma OP. Orbital sonography with its clinico-surgical correlation. Ind J Radiol Imag 2005; 15(4):537-54

12. Javed EA, Chaudhry AA, Ahmad I, Hussain M. Diagnostic applications of "B-Scan". Pak J Ophthalmol 2007; 23(2):80-83

13. Maresova K, Kalitova J, Simicak J, Rehak J. The ultrasound findings in post-traumatic endophthalmitis. Cesk Slov Oftalmol 2006; 62(2):125-32

14. Maneschg O, Csakany B, Nemeth J. Ultrasonographic findings in endophthalmitis following cataract surgery: a review of 81 cases. Ophthalmologe 2009; 106(11):1012-15 